\title{
Basic income, unemployment and job scarcity
}

\author{
Loek Groot \\ SISWO/Netherlands Institute for the Social Sciences \\ and ASSR/Amsterdam School of Social Research
}

\section{Introduction}

The debate on basic income (henceforth BI) seems to be contra-cyclical. The underlying reason for the coming and going of $\mathrm{BI}$ in and out of the picture, is the relationship between the welfare state and unemployment. In periods of recession, e.g. the 1930s, and late 1970s and early 1980s, there are more discussions about $\mathrm{BI}$ than in periods of economic prosperity (e.g. during the so-called Golden Age of capitalism in the 1950s and 1960s). If unemployment is high and to a large extent involuntary, the policy to push the unemployed to accept (non-existent) jobs or to curtail social benefits becomes highly controversial, and as a corollary, forms of BI (a negative income tax, or a participation income) become more fashionable. Unemployment, in particularly large scale and long lasting unemployment, can safely be considered as one of the greatest problems for social policy makers. In the literature concerning the labour market and social policy, one not only finds theories that try to explain unemployment, but also many proposals to reduce or eliminate unemployment. These vary from piece-meal socialengineering approaches (e.g., cutting back social benefit and minimum wage levels, providing wage subsidies to low-waged labour), workfare-oriented approaches, to proposals which envisage an entirely different institutional framework of the labour market (e.g. Weitzman's (1984) Share Economy).

Whereas social policy makers and politicians must face the problems of the day, theorists have the prerogative and opportunity to indulge in fantasies and utopias. Behind their desk they can construct imaginary societies with institutions we never had the opportunity to experience in the real world. The BI proposal is such an imaginary construct. It would mean a 
major break with the means-tested and work-related social security systems now in force in most Western-European countries. ${ }^{1}$ Some even speak of a new paradigm of social security based on the notion of fairness, beyond the present welfare state based on the principles of (Bismarckian) insurance and (Beveridgean) solidarity. ${ }^{2}$ In the literature about BI, the link between BI (or the equivalent negative income tax) and unemployment is not scrutinized, despite the strong correlation between the intensity of the debate on $\mathrm{BI}$ as an alternative to the present, conditional, scheme of social security and the unemployment rate. ${ }^{3}$

The main aim of this paper is to make plausible the claim that to the extent a BI can be justified by giving everyone equal and tradable claims to scarce job assets, the case for a BI is stronger, and that the level of BI should be higher, the higher the level of structural unemployment. ${ }^{4}$ Structural unemployment is taken here in a broad sense:it refers to an objective shortage of jobs. For instance, even if the official unemployment rate would be close to zero, there might still be a considerable shortage of jobs, manifested by a large number of (notably female) persons, not entitled to social benefits, but willing to do paid work. For this reason and by lack of a better term I will use interchangebly the terms job shortage or structural unemployment. It is important to note that, perhaps contrary to the textbook definition of the term unemployment as those who are willing, able and looking for work at the going wage rate, structural unemployment as meant here also includes all those who are not doing paid work, perhaps not even looking for work. To highlight the link between BI and unemployment, the BI scheme will be compared with the Labour Rights scheme as devised by Hamminga $(1992 ; 1995)$, in which shortage of jobs is the point of departure motivating the whole exercize.

The purpose of this paper is twofold. Firstly, sections 2 to 4 discuss the equivalence between a Labour Right and BI system. Section 2 briefly outlines Hamminga's thought experiment, and in section 3 a formal model of the Labour Rights scheme is presented. Section 4 deals with the BI scheme. Secondly, in sections 5 and 6 the insights obtained from the analysis are used to critically examine welfare policies during economic up- and downturns and to evaluate the force of a popular objection against BI, that of exploitation of hard-working citizens. The final section summarizes and concludes.

1 For a recent overview of the potential of $\mathrm{Bl}$ to address the new social question (the division between job holders and non-job holders) pitted against the claims of competing policy instruments (notably wage subsidies), and of the political chances of $\mathrm{Bl}$ in various European countries, see van der Veen and Groot (2000).

2 See Van Parijs (2000), which uses the term Painean justice to characterize unconditional basic social security provided by a Bl.

3 For this correlation, see Groot and van der Veen (2000: 197-9).

4 For a justification of $\mathrm{BI}$ along a different line, that of compensatory justice, see Groot (2002). In the compensatory justice case of $\mathrm{BI}$ unemployment also plays an important role. 


\section{Hamminga's thought experiment}

In a provoking thought experiment Hamminga considers a country $\mathrm{Eu}$ in which there are more workers than there are jobs available, but where everyone is given an equal and tradable entitlement to these scarce job assets. ${ }^{5}$ Thus, the basic idea behind it is simply that a fair way of dealing with a shortage of jobs is to give everyone an equal and tradable share of Labour Rights. Doing this avoids a first-come, first-served appropriation of jobs (and assigning a social benefit to those who lose out), as well as make redundant measures like collective working time reduction to spread jobs over more workers. The Labour Rights scheme can thus be considered as a mechanism to (re)distribute unemployment in an efficient and equitable way. ${ }^{6} \mathrm{~A}$ market of tradable Labour Rights will have the nice result that workaholics will buy the Labour Rights of those with a low propensity to work, against an equilibrium price at which there are no non-workers who prefer to work, nor workers who prefer not to work and to cash in the market value of their share of Labour Rights. Consequently, in Eu it makes no sense to moralize about the level of the unemployment benefit, or whether or not able-bodied persons have a duty to work. ${ }^{7}$ The main advantage of this system is that we get rid of both involuntary unemployment and involuntary employment. To see this consider Table 1, which classifies the labour force under the present conditional system into four categories, according to whether one is, voluntary or involuntary, employed or unemployed.

Table 1. Classification of the labour force according to labour market and motivational status under conditional social security (Hamminga (1995:27), Table 1: A Typology of Employment, adjusted).

\begin{tabular}{|c|c|c|}
\hline Labour force & Voluntary & Involuntary \\
\hline Employed & $\mathrm{A}$ & $\mathrm{B}$ \\
\hline Unemployed & $\mathrm{D}$ & $\mathrm{C}$ \\
\hline
\end{tabular}

Given the level of the unemployment or social assistance benefit, those in $\mathrm{B}$ want to be in $\mathrm{D}$, while those in position $\mathrm{C}$ want to be in $\mathrm{A}$. In the

5 In a country Eu there are five million able-bodied adult citizens, but only four million full-time jobs. The Eugovernment gives everyone four Labour Rights, but to occupy a job one need to return five Labour Rights to the government. In total 20 million Labour Rights are issued by the government and also 20 million are needed for the four million jobs available. The one million people choosing to be unemployed, that is, those with a high preference for leisure, sell their Labour Rights to those who prefer, at the prevailing market price of Labour Rights, to work.

6 Of course, those who think that job rights should not be traded freely because everyone has a moral obligation to work would opt for mandatory job-sharing and maintain unemployment benefits under a work test.

7 "In Eu, there's no discussion of whether people ought to work. It is not a matter of morals or politics or ethics. Jobs are like cars and concerts. Opting for employment is a matter of taste and your own preferred way of enjoying life" (Hamminga 1995 : 26). 
Labour Right system it is only possible to be in A or D, because members of $C$ will buy the Labour Rights (and thus take over the jobs) from $B$ and become A's while those formerly in $B$ move to category $D$. In Eu we have therefore only voluntary employment and voluntary unemployment, where the level of employment is determined by the number of jobs available, while the level of the unemployment benefit is determined by the equilibrium price of Labour Rights. The different manners of how members of group D are treated in both systems is strikingly described by Hamminga as: "Here, they are often distrusted, and we tend to feel no 'responsibility' for them: we do not want to feed them out of 'our' income for which we have the decency to work. $\mathrm{D}$ members are also a very useful symbol and instrument of demagogues who argue in favour of reducing unemployment benefits... In $\mathrm{Eu}$, their presence is highly appreciated. They are the hard core of the supply side of the market in Labour Rights : they help keep down the price" (ibid. : 32). Contrary to the present system of social security, the preferences of all are reflected in the market price of Labour Rights. To sum up : "In Eu's free market, all these preferences (LG : of those originally positioned in A, $\mathrm{B}, \mathrm{C}$ or $\mathrm{D}$ ) would be reflected in prices for which Labour Rights are bought and sold. In our world, it is otherwise. We moralize, making it a matter of politics and collective compromise. We concoct complicated criteria for deciding which inactive able-bodied adult citizens may receive a benefit, for determining the rate of the benefit, for deciding who is going to pay for it and how much. To Eunians, we look like communists deliberately organizing market failures for the sake of nineteenth-century morals" (ibid.:27).

The vantage point of the thought experiment is that it offers a very instructive device which compels us to (re)think how we treat the unemployed and what role the distinction between involuntary and voluntary unemployed, or between 'deserving' and 'undeserving', plays. The experiment also shows that if unemployment is structural so that we have to face a long-lasting scarcity of jobs, the sacrifice of the workers (the price they have to pay for additional Labour Rights to secure a full-time job, and in this way pay for the unemployment benefits) mirrors the sacrifice of the unemployed to give up their right to work. ${ }^{8}$ In discussing Hamminga's thought experiment, Goodin (1998: 188fn) rightly notes that "What they are doing for us is occupying slots among the unemployed that someone has to occupy, in an economy with any appreciable level of structural unemployment; and enemployment benefits can be conceived as payments to them for that service". The 'taxes' paid by the workers to finance social security is not because of solidarity with the unemployed, but reflects a scarcity price which each one choosing to work pays because of self-interest. The solidarity of this system is so to speak a side-effect of the pursuit of self-interest by workers and nonworkers alike. Despite these advantages in terms of fairness and efficiency, it is perhaps fair to say that in real world politics a full-fledged Labour Rights

8 It cannot be ruled out that the unemployment benefit will even be higher than the net wage of those with a low productivity but a high preference to work, or even higher than the average net wage - this would be the case if to work is on balance not a sacrifice at all. 
system is far less likely to be considered as a proposal worth to be taken seriously as an alternative to present social security than a BI or negative income tax scheme. However, it will be shown that a Labour Right scheme is almost fully equivalent with a BI scheme, and therefore the advantages of the former, listed above, apply as well to the latter scheme.

The main question to be answered then is what the level of the BI should be when there is not enough paid work for everyone. Finding a satisfying answer to this question is also of paramount importance to the ongoing debate on the justice of the BI proposal. Prominent defenders of a BI like van der Veen and van Parijs ${ }^{9}$ argue that a flat tax financed BI, at the highest feasible level, combining the simplest possible income tax with the simplest possible welfare system, is also the most just scheme within the framework of liberal-egalitarian justice. Is this too good to be true? A quick way to answer in the affirmative is to say that a substantial BI, sufficient to meet subsistence needs, is economically infeasible. ${ }^{10}$ For the sake of argument, the question of economic (in)feasibility ${ }^{11}$ will be ignored, and instead I concentrate on another important, and in this context more relevant, objection, that of exploitation. This is taken up in section 6 , in which the force of the objection is considered by relating it to the insights gained from the comparison of the BI and Labour Rights schemes.

\section{The Labour Rights scheme}

\subsection{Uniform productivity levels}

In the experiment as described by Hamminga (1995, see also footnote 5 above) a homogeneous population (that is, with equal earning capacities) is assumed, with only a choice between full-time work or full-time leisure. In what follows, these simplifying assumptions will be lifted sequentially.

Consider an economy in which the maximum feasible employment level, in proportion to the labour force, is $f$ (so $f$ is the ratio between the number of full-time equivalent jobs ${ }^{12}$ and the labour force), with $f<1$.

9 See van der Veen (1991) and van Parijs (1995).

10 Or some variation on this, like a BI is either too low to be socially acceptable or too high to be economically feasible.

11 My stance is that this question is not answerable, taking into account the radical uncertainty surrounding the effects (on human capital formation, saving, investment, profits, migration, informal work, elc.) of a BI scheme. Based on theory and empirical research we can say something about which kinds of effects most likely will result, specified by groups (e.g. low wage earners, high wage earners, welfare recipients), but not or hardly anything about the total effects of such a major change of conditional to unconditional social security. Bearing in mind that there is even no consensus among economists on the economic effects of a small change in the level the statutory minimum wage, it can safely be taken for granted that economists are not able to make a reliable prediction of the total impact of the many effects which would be brought about by the implementation of a BI.

12 Two part-time jobs of half a standard work week count as equivalent to one full-time job. 
The government, acknowledging this shortage of jobs, decides to give every member of the labour force (including those not working or looking for work) $p$ Labour Rights, with $0<p \leqslant f \leqslant 1$. If someone wants to work full-time, she has to buy an additional amount or share of $(1-p)$ Labour Rights on top of the $p$ Labour Rights which she holds already in possession. Any worker can thus freely decide how many hours of a standard work week to work by selling or buying the required amount of Labour Rights. Since we first maintain the assumption of equal talents (and equal wages), the price to be paid for additional Labour Rights $(p)$ can be interpreted as a proportional tax on labour income $(w)$. Eunians then face the following budget constraint :

$$
Y=[w-p] L+p p \quad L \in[0,1]
$$

with labour supply, ${ }^{13}{ }^{14} L$ :

$$
L=e[w-p] \quad e \in[0,1]
$$

where the parameter $e$ expresses the, individual specific, propensity to perform paid work. Those with $e=0$ are the most work-averse (preferring a leisure-oriented life), while those with $e=1$ are the workaholics. ${ }^{15}$ According to Eq. (1), since each member of the workforce receives $p$ Labour Rights at the beginning, and given a uniform market price of $p$, the income resulting from selling one's Labour Rights (so $L=0$ ) is equal to $p p$. Likewise, someone who just decides to perform paid work during a fraction $p$ of a full-time work week does not have to buy additional Labour Rights, nor has to sell any Labour Rights, and receives income $w p$. Those who wish to work longer than $p$ (times the number of hours of a standard full-time work week) have to buy additional Labour Rights. For example, a full-time worker with $L=1$ has to buy $(1-p)$ additional Labour Rights on top of the $p$ Labour Rights which this worker already holds in possession. In effect, the scheme is essentially an auction between work-adverse and work-hungry citizens.

13 It can be easily derived that the labour supply function according to Eq. (2) corresponds to the utility function $U(Y, L)=Y-\frac{2}{2}$, where the second term on the RHS represents the burden of work.

14 Note that this labour supply function has no income effect and a unitary elasticity with respect to the net wage. Empirical research invariably finds that male labour supply is rather inelastic (close to zero), while female labour supply is somewhat more elastic, but its elasticity also well below unity. One can easily adjust the labour supply function (2) for varying elasticities, through specifying $L=e[w-p]$, so that the elasticity is equal to $\varepsilon$. However, this would make the analysis much more complicated. The main thing to bear in mind is that the level of unemployment income (or BI) can be much higher with inelastic labour supply than the levels which follow from the analysis here.

15 This way to model preferences for work and leisure in the utility function, as well as some other assumptions made and results used, are the same as in Chapter 3 of the dissertation of Vandenbroucke (2001). 
The equilibrium condition for the market of Labour Rights can be expressed as follows : ${ }^{16}$

$$
\int L f(e) d(e)=p
$$

stating that total labour supply must equal the employment level chosen by the government $(f(e)$ is the density function of parameter $e$ ). Substitution of (2) into (3) and solving for $p$ gives the following shorthand expression for $p$, the price to be paid for a coupon of Labour Rights :

$$
p=\frac{\bar{e} w-p}{\bar{e}}
$$

Fixing the uniform wage rate at unity, and given that shortage of jobs is the point of departure motivating the whole exercize, the price of Labour Rights is higher, the higher is the average propensity to work $\bar{e}$ and the lower the chosen employment level $p$. (If everyone's share of Labour Rights is higher than $\bar{e}$, then there is excess supply of Labour Rights, which causes the price of a Labour Right to dwindle to zero. ${ }^{17}$ ) The logic behind the Labour Right market is that the net money income of a full-time worker will be lower, the lower the pre-established employment share $p$ (which makes jobs more scarce) and the higher the average preference to work (indicating that many others want to work hard, which is to the advantage of those who have a low preference for working). Non-labour income, that is money income resulting from selling one's initial share $p$ of Labour Rights against the market price $p$, is maximized for that value of $p$ for which :

$$
\frac{\partial(p p)}{\partial p}=0 \Rightarrow p_{\max }=\frac{\bar{e} w}{2}
$$

where $p \quad$ denotes the participation rate which maximizes the unemployment benefit. The relationships between the unemployment benefit $p p$ and the market clearing price of Labour Rights and different values of the preestablished participation rate $p$, with preferences $(\bar{e})$ held constant, are illustrated in Figure 1.

The interrupted line shows that $p$ is a declining function of $p$ and equal to zero if $p$ is equal to $\bar{e}$, and that the unemployment benefit,

16 Alternatively, one might specify this as either (3) $\int_{0}^{p}(p-L) f(e) d(e)=\int_{p}^{1}(L-p) f(e) d(e)$

or (3") $\int L p f(e) d(e)=p p$. According to (3'), the amount of Labour Rights sold (the LHS) must equal the amount of Labour Rights bought, where $e$ is the propensity to work of someone who chooses to work exactly p. Eq. (3") is the usual balanced budget, stating that (tax) revenues must equal social outlays.

17 If $\bar{e}<p$, the price of Labour Rights would become negative only if everyone is enforced to exercize the Labour Rights, that is either to work more than some may want to or to find someone who is prepared to take over Labour Rights. 
Figure 1: The price of Labour Rights ( $p$ ) and the level of the unemployment benefit ( $p p$ ) as a function of the participation rate $p$.

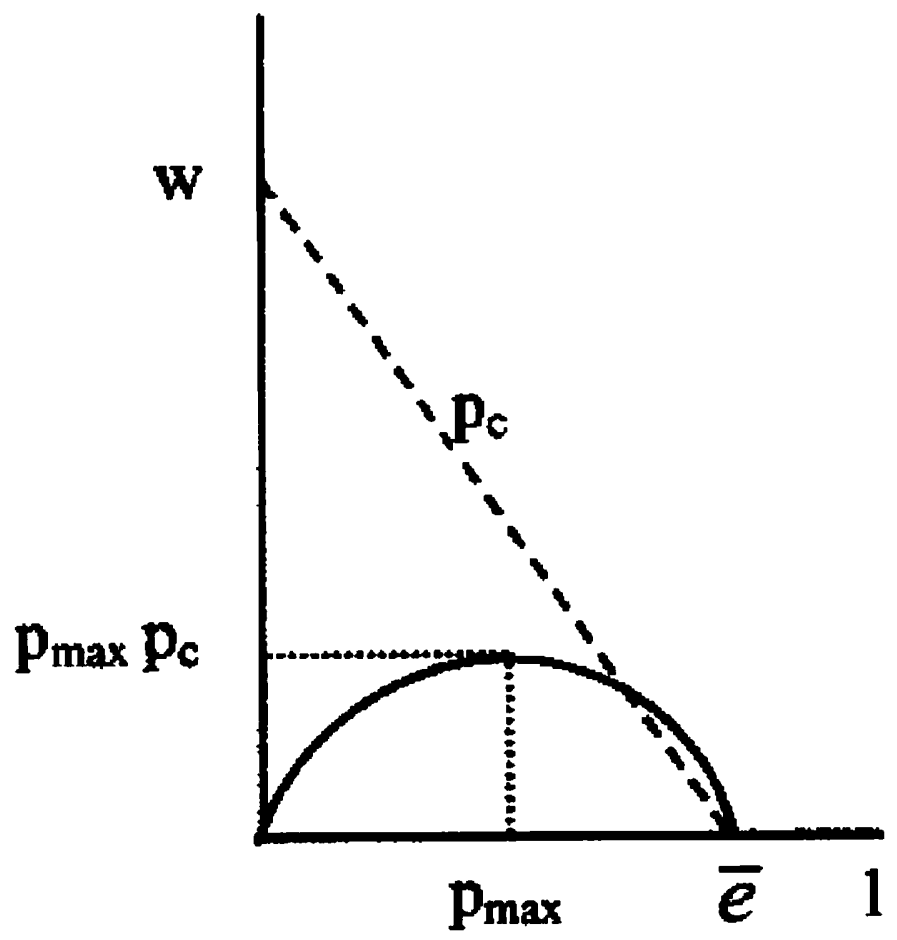

Participation rate $\rightarrow$

represented by the solid line, shows a hump-shaped curve. For $p$ less than $p$, the price of Labour Rights is high because jobs are scarce, but anyone choosing not to work has only a small share $p$ of Labour Rights to sell to those who want to work more than their share. One can also take it in this way, that for a low $p$ there are relatively few workers doing paid work and many abstaining from paid work, which implies a low average income for both workers and non-workers. If $p$ is higher than $p \quad$, e.g., close to $\bar{e}$, then jobs are not so scarce and the price for a Labour Rights is consequently low. The fact that non-workers can sell a larger share of Labour Rights compared to the situation where $p$ is equal to $p$ does not compensate the lower price of Labour Rights.

To summarize, given the value of $\bar{e}$, we can determine the share of Labour Rights ( $p$ ) to be distributed equally to all which maximizes the non-labour unemployment income $\left(\begin{array}{ll}p & p\end{array}\right)$. However, so far nothing is said about whether to choose the participation rate which maximizes the unemployment benefit is also just. It may well be that the maximum feasible 
overall employment level or participation rate is far higher than the rather low participation rate which maximizes the unemployment benefit. Note that the pre-established participation rate $p$ determines how large a share of a full-time job right each member of the labour force receives. According to Eq. (4), the market price $p$ for a Labour Right approaches zero if $p$ approaches $\bar{e}$. It is favourable to those with a high preference for work if the government sets the overall participation rate close to the maximum feasible rate, while the hard core of the voluntary unemployed would favour a participation rate which is close to the rate $p$ which maximizes their unemployment benefit. The question then arises which rate the government must choose. ${ }^{18}$ Instead of artificially constraining the number of jobs in order to maximize the unemployment benefit, it is perfectly equitable to choose the feasible employment level $f$ : whatever its level turns out to be. If $f$ is far higher than $p$, we feel sorry for the leisure-lovers, but they have no valid complaint. Equally, if $f$ is equal to or close to $p$, we feel sorry for the workaholics, but they have no valid complaint either. In both cases, everyone has equal access to jobs, and given equal productive talents, everyone has also equal opportunities to convert leisure into money income. There is no injustice. This issue is taken up again in section 4 when discussing the BI scheme.

\subsection{Non-uniform productivity}

If the assumption of equal earning capacities (a uniform $w$ ) is removed, we encounter the problem that in the original set up of the experiment the price to be paid for additional shares of Labour Rights is essentially a tax imposed on workers proportional to working time, but not proportional to their earning capacity. It thereby violates an important principle of tax equity, namely that everyone pays according to one's means. For someone with a rather low earning capacity, but a high preference to work, the tax in the form of the price of additional Labour Rights may constitute a serious obstacle to choose the option of full-time work, whereas for someone with an extremely high earning capacity, it is not more than a tip. In order to circumvent this problem, just assume that all workers pay a tax proportional to their earning capacity $w$ and their labour supply. Accordingly, the budget constraint and labour supply function become :

$$
Y=[(1-t) w] L+p p \quad w \in[w, 1],
$$

and

$$
L=e[(1-t) w]
$$

18 This problem turns out to be quite tricky, not only because of the opposing interests of workaholics and leisure-lovers. For instance, the maximum feasible rate is higher if the conditions to classify jobs offered by employers as proper jobs, are loose : do we count the jobs offered by an employer who wants to start a peep-show as proper jobs? Again, it is in the interest of those with a low attachment to paid work to have rather strict criteria (which brings the pre-established rate closer to $p$ ), while it is in the interests of full-time workers and employers that rather loose criteria are used. 
According to (6), those who choose not to work receive unemployment benefits reflecting the scarcity value of jobs, and all workers pay for appropriating scarce job assets in proportion to earning income. Someone who works full-time is a net tax recipient or contributor dependent on whether (earning power related) taxes paid $(t w)$ is smaller or greater than the uniform benefits received ( $p p$ ).

Now the equilibrium condition for the market for Labour Rights and the balanced budget no longer coincides (see footnote 16). Instead, we have two separate conditions :

$$
\iint L f(e) f(w) d(e) d(w)=p
$$

and

$$
\iint t w L f(e) f(w) d(e) d(w)=p p
$$

Eq. (8) describes that aggregate labour supply must be equal to the employment level $p$, and Eq. (9) that tax revenues (the LHS) must equal total social expenditures (the RHS). For simplicity, assume that $e$ and $w$ are distributed independently. Substituting (7) into (8) and solving for $t$ gives:

$$
t=1-\frac{p}{\bar{e} \bar{w}}
$$

and solving (9): 19

$$
p p=\bar{e} t(1-t)\left(\bar{w}^{2}+\sigma^{2}\right)
$$

For those who want to live merely from the proceeds of selling Labour Rights, the tax rate which maximizes their non-labour income can be derived from :

$$
\frac{\partial(p p)}{\partial t}=0 \Rightarrow t_{\max }=\frac{1}{2}
$$

corresponding to (see Eq. (10)) $p_{\max }=\bar{e} \bar{w} / 2$, the same as we found in the case of a homogeneous workforce, except that the uniform wage rate $w$ is now replaced by the average productivity $\bar{w}$. However, it is far from obvious that an egalitarian government, faced with the problem of scarcity of jobs, should aim at maximizing the income of those who want to indulge in leisure. Instead, the maximin objective requires to maximize the income of the group of least advantaged (those with the lowest productivity level $w$ ),

19 Making use of the fact that $\int w^{2} f(w) d(w)=\bar{w}^{2}+\sigma^{2}$ 
and to weight preferences impartially. Doing this requires (the subscript $L$ denotes the lowest productivity level) :

$$
\max \int Y=\max \int[(1-t) w] L+p p
$$

Substituting (7) for $L$ and (11) for $p p$ in (13) and differentiating with respect to $t$ gives :

$$
t^{*}=1-\frac{\left(\bar{w}^{2}+\sigma^{2}\right)}{2\left(\bar{w}^{2}+\sigma^{2}-w^{2}\right)},
$$

so for $w>0, t^{*}$ is lower than $t$. It can easily be checked (by solving Eq. (14) for $t^{*}=0$ ) that as $w$ approaches $\bar{w}$, so that $\sigma^{2}$ gets smaller and smaller, $t^{*}$ tends to zero : if all have more or less the same productivity $w$, and the same access to jobs, then there is no rationale for taxation and redistribution. At the other extreme, if $w$ is zero, the least productive are not able to capture any labour income, so the best thing for them to do is to sell their Labour Rights, and the best thing for an egalitarian government to do for them is to set the tax rate at the Laffer turning point $t \quad$ which maximizes non-labour income. The higher the value of $w$, the lower the required tax rate to achieve the maximin objective (13), and therefore (see Eq. (10)), the closer the employment level $p$ approaches the maximum feasible level $f$. Admittedly, to ration artificially the employment level below the maximum feasible level is probably an outcome hard to swallow, especially if we bear in mind that the whole exercise departs from the presumption that scarcity of jobs is the main problem. For several reasons this outcome is nonetheless acceptable. Firstly, suppose that instead of rationing the employment level the government would allow everyone to work as much, but not more, as what corresponds to everyone's legitimate share of Labour Rights. This would amount to giving each member of the labour force an untradable share of Labour Rights equal to the feasible rate $f$. This measure is equivalent with a compulsory working time reduction of all full-time jobs of $(1-f)$ percent. It is clear that there will be ample room for Pareto-improvements if Labour Rights would be tradable: those wanting to work longer than $f$ hours of a standard work week would be eager to pay a price for additional Labour Rights from those who want to work less than $f$ hours. It is the tradability of Labour Rights which ensures that all possible Pareto-improvements can be realized. Therefore, in a world of equal entitlement to job rights to deal with job shortage there is an efficiency case for the Labour Rights scheme. Secondly, the fact that $p<f$ only results because the government wants to maximize the income of the least advantaged. In a sense, then, the divergence between $f$ and $p$ can be interpreted as the cost in terms of employment of providing social security, with $f$ the employment level in an economy without any or only minimal social security. One more reason why the result of putting a ceiling to the employment level should not bother us at this moment has to do with 
the fact that it is only a thought experiment. As will be shown in the next section, the problem does not show up in this guise under an equivalent BI scheme.

\section{The equivalent basic income scheme}

\subsection{Uniform productivity levels}

A flat tax BI scheme (or a single tiered NIT scheme) is fully characterized by two parameters : the level of the BI (or the NIT income guarantee) and the tax rate. ${ }^{20}$ Below, the set of equations describing a BI scheme are presented, where apostrophes are used to indicate the equivalence with the model with Labour Rights. The budget constraint under a BI scheme is :

$$
Y=[w(1-t)] L+B
$$

with $B$ denoting basic income. The labour supply function (2) does not change except that $(w-p)$ becomes $w(1-t)$, and instead of Eq. (3) we have the balanced budget equation:

$$
\int t w L=B
$$

which gives :

$$
B=\bar{e}\left[t(1-t) w^{2}\right]
$$

Differentiating Eq. (4') with respect to $t$ gives the $B$-maximizing tax rate $t=\frac{1}{2}$. Using Eq. (2), the participation rate corresponding to this tax rate is $\int\left(L \mid t=\frac{1}{2}\right)=\frac{-}{2}$, the same value as we found before in the scheme of Labour Rights. The relation between $B, L$ and the tax rate is shown in Figure 2.

It can easily be verified that Eq. (1') is equivalent with Eq. (1) above if $t w$ is equal to $p$ and $B$ is equal to $p p$. Denote $t$ as the tax rate which realizes a participation rate of $p$, so:

$$
\int L \mid t \equiv p \Rightarrow \bar{e} w(1-t)=p \Rightarrow t w=\frac{\bar{e} w-p}{\bar{e}}=p
$$

which establishes the formal equivalence between both schemes. The only difference between both schemes is this: in the Labour Rights scheme the government must choose beforehand the participation rate $p$ (which

20 See Atkinson (1995) for an extensive treatment of the Bl/flat tax proposal. 
Figure 2: The level of basic income $B$ and labour supply $L$ as a function of the tax rate $t$.

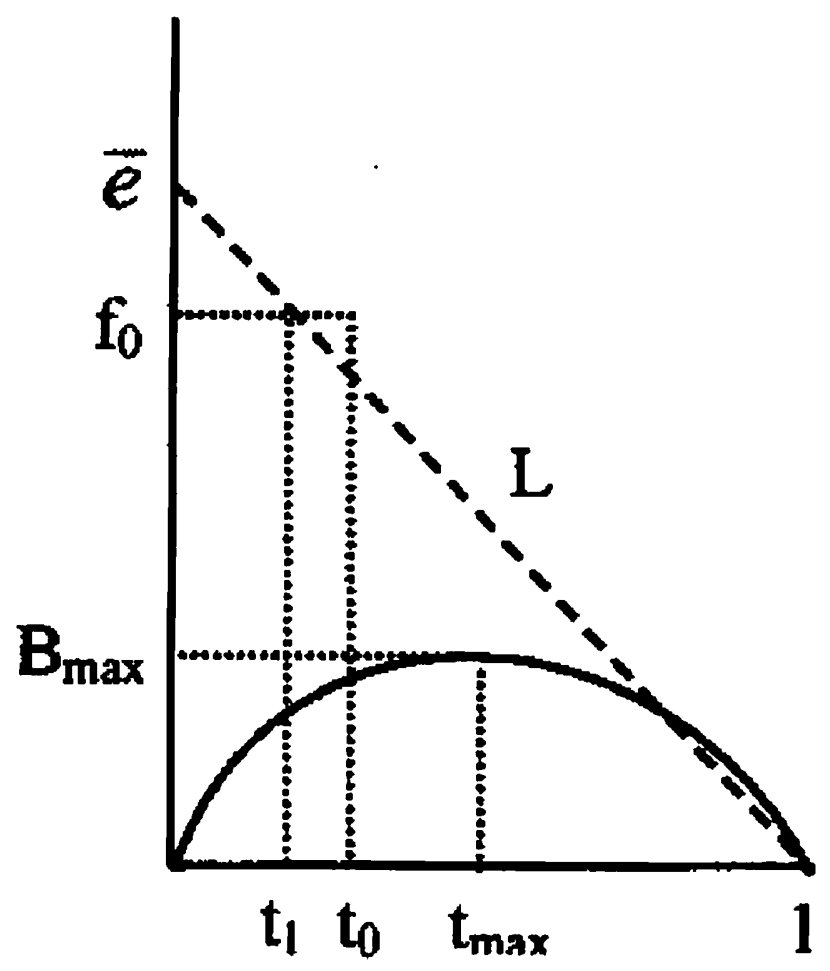

Tax rate $\rightarrow$

determines how large a share of tradable job rights everyone is granted), which in turn determines, given $\bar{e}$, the value of $p$ (the 'tax rate') and hence the level of the unemployment benefit; under the BI scheme, the government has to decide beforehand which tax rate to impose, which as a matter of fact simultaneously determines the overall participation rate and the level of $B$. In the former scheme, the participation rate $p$ is taken as an exogenous variable while the 'tax rate' $p$ and the level of the unemployment benefit are endogenous; in the latter scheme the tax rate is exogenous, while the participation rate and the level of $B$ are endogenous.

The right procedure for the government to follow is to choose a tax rate $t_{0}$, and to check whether there are still vacancies left (so $f_{0}>L$ at $t=t_{0}$, see Figure 2). If so, the tax level and the level of $B$ are too high, causing labour supply to be insufficient to fill all jobs available. Next, lower the tax rate (to $t_{1}$ ) as well as $B$, so inducing a higher labour supply, until all job vacancies are disappeared. If, on the other hand, at $t=t_{0}$, there are people searching in vain for a job (so $f_{0}<L$ at $t=t_{0}$ ), then labour supply is too high compared to the number of jobs. To reach equilibrium on the 
labour market, the government can raise the level of $t$ as well as $B$, inducing a decline in labour supply, until labour supply matches labour demand. In conformity with the Labour Rights system (see Table 1 in section 2), at the market clearing levels of $t$ and $B$, there is now only voluntary unemployment and voluntary employment.

\subsection{Non-uniform productivity}

With unequal talents, we can simply maintain Eqs. (1') and (3'), but interpret $w$ as a varying parameter. Solving (3') gives:

$$
B=\bar{e} t(1-t)\left(\bar{w}^{2}+\sigma^{2}\right)
$$

so the tax rate that maximizes $B$ is $t=\frac{1}{2}$. By equating $\iint L=p \Rightarrow$ $t=1-\cdots$, which matches exactly Eq. (10) of the Labour Rights system, it follows that labour supply at $t=\frac{1}{2}$ is equal to $\bar{e} \bar{w} / 2$. Given that both systems are equivalent, it will not come as a surprise that solving Eq. (13), with $p p$ replaced by $B$, that is maximizing average income of the group with lowest productivity, yields the same tax rate $t^{*}$ as expressed in Eq. (14).

\section{$5 \quad$ Welfare policy and economic up- and downturns}

Now that we have some insight in the functioning of a Labour Rights and the equivalent $\mathrm{BI}$ scheme, it is interesting to see how these schemes react, to exogenous economic shocks, compared to how welfare policy usually accommodates changes in the economic environment. It is taken for granted that labour demand is always the short side of the labour market (for most European countries, this is a plausible assumption for already more than two decades). Under a Labour Rights scheme, a positive shock to the economy would allow the government to set the participation rate $p$ at a higher value, leading to a decline in the level of the unemployment benefit ${ }^{21}$ (provided $p>p \quad$ ). In terms of Figure 1, the economy moves further to the right, away from $p$. Under a BI scheme, a positive shock (an increase in labour demand at prevailing wages) effects a decline in the level of $B$. In terms of Figure 2, the tax rate must be set at a lower level to foster labour supply in order to absorb higher labour demand, so the economy moves to the left, e.g. from $t_{0}$ to $t_{1}$, away from $t$. This may come as a surprise, but it is in line with the central assertion of the analysis that the legitimate level of $B$ is lower, the lower the level of unemployment due to shortage of jobs. The limiting case is where there is no shortage of jobs at all, in which case the

21 Which is of course necessary to stimulate labour supply, or in terms of Table 1, to give some members of group D (the voluntary unemployed) the incentive to become members of group $A$ (the voluntary employed). 
legitimate level of $B$ is nil under the assumption of equal talents. ${ }^{22}$ Under the existent conditional welfare scheme, a positive shock also reduces the number of unemployed. The difference is that a lower unemployment rate removes somewhat the pressure to lower social benefits: if anything, the higher tax revenues and lower social security outlays allows in principle to raise the social benefit and to lower tax rates.

In an economic downturn, this picture is reversed. Under a Labour Rights system, the participation rate declines and unemployment benefits increase (which is necessary to induce more workers (members of group A according to Table 1) to voluntarily abstain from paid work and to become voluntarily unemployed (D)). The same is true under the equivalent BI scheme: a higher tax rate is required to reduce total labour supply until it equals labour demand (which as a result of the economic downturn decreases). Under both schemes, the economy moves closer to $p$ (again, provided the participation rate before the shock occurs was higher than $p \quad$ ). The usual welfare policy, the best remedy under the existent social security scheme so to speak, to overcome an economic downturn and the problems this poses for the welfare state is to curtail social benefits. Why?

The first reason one can think of is that lower social benefits effects a higher labour supply because it is usually assumed that the latter varies inversely with the replacement ratio. However, even if all unemployment before the shock occurs was voluntary, this measure is unnecessary because some workers will lose their job and become involuntary unemployed. An economic downturn will thus inevitably, even if social benefit levels are maintained, create involuntary unemployment (exerting a downward pressure on wages) which suggests that it is unnecessary to further stimulate (excess) labour supply and downward pressure on wages through cutting social benefits. The second reason is that higher unemployment exerts an upward pressure on tax rates because of increasing social security outlays, which in turn raises gross wages (and hence would even aggravate the decline in labour demand, leading to a vicuous circle). This kind of reasoning implicitly assumes that those who remain at work do not accept a decline in net wages despite the economic downturn. If this is true (and this is very plausible, since insiders have sufficient power and job security to refuse net wage cuts), it means that only the unemployed must carry the burden of overcoming the economic downturn: lower social benefits allows lower tax rates and, given the level of net wages, lower gross wage costs for employers. To be sure, the economic downturn can then only be overcome when the higher labour supply and lower tax rates indeed lead to lower gross wage levels. To summarize, the difference in adjustment to a negative shock between the Labour Rights and BI scheme on the one hand and the welfare policy under the existent scheme on the other is that the former schemes just try to make all (un)employment voluntary (which requires

Or positive in the case of unequal talents, not because of shortage of jobs, but merely because the government uses the redistributing instrument of $B$ to maximize the average income of the least advantaged. 
higher unemployment benefits and lower net wages for workers), while the latter always tries to return to a state of full employment (whether voluntary or involuntary), if necessary by means of cutting social benefits. ${ }^{23}$ Under the Labour Rights and BI schemes, at each level of unemployment the unemployment benefit or BI is set at that level at which all (un)employed are in that position voluntarily; the higher the level of structural unemployment, the higher the required level of income for the unemployed to induce sufficient workers to choose for unemployment.

\section{Exploitation}

The exploitation objection against BI, formulated by Elster (1986:719), runs as follows: "Most workers would, correctly in my opinion, see the proposal as a recipe for the exploitation of the industrious by the lazy". The exploitation objection must be distinguished from the reciprocity-based parasitism-objection, which says 'no benefit without work' (see e.g. White 1997). In the latter, the reciprocity-based duty to work (those who can work should not be entitled to social benefits) is at stake, while in the former the lower standard of living of workers in virtue of supporting the parasites is involved. However, if there is a shortage of jobs, and no shortage of qualified workers prepared to occupy these jobs, it makes less sense to force unemployed workers to meet the demands of reciprocity. Probably White $(1997: 82)$ might accord with this view since he writes : "Since it is only fair to insist on satisfaction of the reciprocity principle if there are sufficient opportunities for citizens to do so, it would arguably become unfair to continue to affirm the principle were we unable to return to full employment (in an appropriately modernised sense). The case for citizen's income (basic income) would then be correspondingly stronger." If one nevertheless wants to hold fast to the demands of reciprocity, then the workaholic must give up part of his full-time job.

Needless to say, the framework expounded in the previous sections also offers an exquisite opportunity to evaluate the merits of the exploitation objection, even more than the parasitism objection. As a first reply one might say that under a BI (or Labour Rights) scheme any worker has the opportunity to choose a fully leisurely life-style, so those workers who feel exploited can immediately switch to a situation with full-time leisure. This reply will not do, because it is just the moral rightness of providing unconditional income transfers paid for by others which is at stake. Moreover, in the counterfactual case that indeed everyone would take this opportunity, there is no BI to dispense. The real interesting question

23 Note that the relevance of this conclusion, and also of this paper, becomes much greater if we interpret the existing social benefits as conditional on means only, while the work-test is merely formal (to fulfil the formal duty to work, the unemployed only have to visit regurlarly the job centre to see that no job vacancies comes along). In that case, voluntary unemployment is, not in theory but in practice, tolerated. 
is therefore to figure out what reasonable complaints workers may have when the BI turns out to be economically feasible, that is, at a level where enough persons want to convert leisure time into additional money income (on top of their BI) by means of paid labour (and so keeping that level of BI economically sustainable). Van der Veen (1991:203) replies that “... disgruntled workers have no valid moral complaints against the behaviour of their non-working fellows under a genuinely sustainable universal grant". Now disgruntled workers are those who decide "... to stay in the workforce, even though they would rather quit, [is] explained by the moral motivation of not wanting to be parasitic" (ibidem.). In other words, these workers do have the same preferences regarding work and leisure as those who choose full-time leisure, except that they do not want to live off others labour. Hamminga's experiment is of great help here since under a conditional scheme there is no possibility to test how sincere the opinions of the disgruntled workers are, while the sincerity and the alleged ubiquity of these opinions among workers are put to a real test if Hamminga's proposal for freely tradable Labour Rights in the circumstance of scarcity of jobs is carried out. It might well turn out that the alleged disgruntled workers under a Labour Rights scheme would quickly choose the option to full-time leisure by selling their Labour Rights, if only because this is a perfectly legitimate move under that scheme, and therefore do not attach much importance to the notion that it is morally suspect to live off others labour (which, according to Hamminga, is the official work ethic uphold by the existing work- and means-tested scheme of social security).

Returning to the Labour Rights scheme, if there is a scarcity of jobs due to structural unemployment, we saw that there is room for an unconditional income entitlement, even for those who voluntarily choose to be idle. However, to set it at the highest durably sustainable level (financed by the single proportional tax rate which yields the highest tax revenues, hence the highest feasible unemployment benefit or BI) might be unjust to (and indeed exploiting) all those who want to work hard. The tax rate corresponding to the case where the government tries to maximize the income of the least advantaged, while taking into account the scarcity of jobs, need not be equal to, and probably will be less than, the tax yield and BI maximizing rate. This means that in these circumstances there exists a positive level of the unemployment benefit or BI, albeit less than the highest feasible level, which can withstand Elster's objection : it is not because they are industrious that they have to pay taxes, but because they want to appropriate more than their legitimate share of scarce job assets, and additionally, in the case of unequal talents, because of the required amount of redistribution to improve the position of the least advantaged. Of course, this result only applies to the extent that job scarcity justifies equal and tradable job rights. 


\section{$7 \quad$ Summary and conclusion}

The analysis of this paper is entirely concerned with scarce job assets. However, this methodology of granting equal and tradable rights can be transposed to other areas. For instance, the same approach can be adopted if we are concerned with a just distribution of pollution rights.

The aim of the analysis performed is to investigate whether there is a relation between unemployment and BI. As a starting point it is assumed that for one reason or the other there is scarcity of jobs. The main question is what workers have to pay to appropriate (scarce) jobs assets. Hamminga's proposal to deal with scarcity of jobs is to give each member of the labour force an equal and tradable right to these scarce job assets. It is shown that such a Labour Right system is equivalent with a BI scheme, with the only difference that in the former the level of employment (or participation rate) is exogenous and the 'tax rate' endogenous, whereas under the BI scheme it is the other way around. The equivalence consists in that the price of Labour Rights and the level of the unemployment benefit corresponds to the proportional tax rate and the level of BI respectively. In other words, the single proportional tax rate of a BI scheme can be considered as what workers have to pay to appropriate scarce job assets (and, with unequal talents, for meeting the redistributional objective). Both schemes allow that some people voluntarily abstain from doing paid work, in return for a financial compensation, an unemployment benefit or a BI.

Starting from no scarcity of jobs at all, the level of the unemployment benefit or BI varies positively with the degree of scarcity of jobs until the maximum value is reached. The overall participation rate corresponding with the maximum value of the unemployment benefit or $\mathrm{BI}$ is rather low, certainly when compared with the average preference to do paid work. There is, however, no reason to choose for the maximum sustainable BI. Under equality of talents, the government can simply choose the level of employment which it deems feasible, and let the market in Labour Rights determine the level of the unemployment benefit. Under the BI scheme, the government can set the proportional tax rate (and the level of $B$ ) at the level at which the labour market clears.

The bottom line of the analysis is that the level of BI varies positively with the level of unemployment:more severe scarcity of jobs requires a higher tax rate (and hence a higher BI) to adjust the total labour supply downwards to the number of jobs available. The level of the BI also varies positively with the average preference to work. The logic behind this is that, given the tax rate, more people voluntarily choose to work if the average preference towards work is higher. So in a society with a strong work ethic it is possible to have a high BI as well as a high level of employment. 


\section{References}

Atkinson, A.B. (1995), Public Economics in Action. The Basic Income/Flat Tax Proposal, Oxford, Clarendon Press.

Elster, J. (1986), "Comment on Van der Veen and Van Parijs", Theory and Society, 15, pp. 709-722.

Elster, J. (1989), Solomonic Judgements, Cambridge University Press.

Groot, L. and R. van der Veen (2000), "Clues and Leads in the Policy Debate on Basic Income in the Netherlands", in Robert van der Veen and Loek Groot (eds.), Basic Income on the Agenda : Policy Objectives and Political Chances, Amsterdam University Press, pp. 197-223.

Groot, L.F.M. (2002), Basic Income and Compensatory Justice, Journal of Social Philosophy, 33 (1), pp. 141-161.

Hamminga, B. (1992), Could Jobs be like Cars and Concerts?, unpublished.

Hamminga, B. (1995), "Demoralizing the Labour Market : Could Jobs be like Cars and Concerts?", The Journal of Political Philosophy, 3, pp. 23-35.

Schmidtz, D. and R. Goodin (1998), Social Welfare and Individual Responsibility, Cambridge University Press.

Vandenbroucke, F. (2001), Social Justice and Individual Ethics in an Open Society: Equality, Responsibility, and Incentives, Berlin, SpringerVerlag.

Van der Veen, R.J. (1991), Between Exploitation and Communism. Explorations in the Marxian Theory of Justice and Freedom, Groningen, Wolters-Noordhoff.

Van der Veen, R. and L. Groot (eds.) (2000), Basic Income on the Agenda: Policy Objectives and Political Chances, Amsterdam University Press.

Van Parijs, Ph. (1995), Real Freedom for All: What (if Anything) Can Justify Capitalism?, Oxford, Clarendon Press.

Van Parijs, Ph. (2000), "Delivering a Basic Income: Philippe van Parijs Responds", Boston Review : New Democracy Forum, Oct/Nov.

Weitzman, M.L. (1984), The Share Economy : Conquering Stagflation, Cambridge, Harvard University Press.

White, S. (1997), "Liberal Equality, Exploitation, and the Case for an Unconditional Basic Income", Political Studies, XLV, pp. 312-326. 
